\title{
News media coverage of smoking and health is associated with changes in population rates of smoking cessation but not initiation
}

\author{
John P Pierce, Elizabeth A Gilpin
}

\begin{abstract}
Objective-To determine whether changes in news media coverage of smoking and health issues are associated with changes in smoking behaviour in the USA.

Design and main outcome measuresIssue importance in the US news media is assessed by the number of articles published annually in major magazines indexed in The Reader's Guide to Periodical Literature. Annual incidence rates for cessation and initiation in the USA were computed from the large, representative National Health Interview Surveys (19651992). Patterns in cessation incidence were considered for ages 20-34 years and 35-50 years. Initiation incidence was examined for adolescents (14-17 years) and young adults (18-21 years) of both sexes.

Results-From 1950 to the early 1980s, the annual incidence of cessation in the USA mirrored the pattern of news media coverage of smoking and health, particularly for middle aged smokers. Cessation rates in younger adults increased considerably when secondhand smoke concerns started to increase in the US population. Incidence of initiation in young adults did not start to decline until the beginning of the public health campaign against smoking in the 1960s. Among adolescents, incidence rates did not start to decline until the 1970 s, after the broadcast ban on cigarette advertising.

Conclusions-The level of coverage of smoking and health in the news media may play an important role in determining the rate of population smoking cessation, but not initiation. In countries where cessation has lagged, advocates should work to increase the newsworthiness of smoking and health issues.

(Tobacco Control 2001;10:145-153)

Keywords: initiation; cessation; health; mass media
\end{abstract}

Mass media can influence population smoking either through tobacco industry advertising that promotes the behaviour, ${ }^{1-4}$ or through public health anti-tobacco messages that discourage it..$^{5-9}$ This suggests that coverage of smoking issues in regular media news stories may also be associated with changes in population smoking behaviour. The relative coverage of issues in the news media and public perceptions of the importance of these issues generally correspond closely. ${ }^{10-13}$

News media coverage of health issues is generated by events, ${ }^{14}$ such as news conferences organised by medical journals, the government or voluntary health advocacy agencies. Such conferences are typically arranged to feature new scientific findings, as well as new public policy initiatives. However, the slant such events receive in the news media may depend in part on how the major advocacy groups rally around the issue. ${ }^{14}{ }^{15}$ For example, in the context of smoking and health, population smoking behaviour might be less responsive to new evidence of harm if the news coverage suggested that the evidence was controversial among the relevant experts than if the coverage suggested consensus.

In the past, advocacy groups from the public health and medical fields in the USA have not always been in complete consensus on issues related to smoking and health. ${ }^{17}{ }^{17}$ Following publication of the early evidence that smoking harms health, the US tobacco industry (the opposing advocacy group) initiated extensive public relations damage control efforts to protect its interests. ${ }^{17}$ Below, we briefly review the activities of the various US advocacy groups related to the smoking and health events beginning in 1950 through the early 1980s. More complete histories of these events are published elsewhere. ${ }^{17-20}$

Dissemination of early findings and consensus about smoking and health Although concerns about increasing lung cancer rates were published in the scientific literature in the late 1930s, the first solid evidence that smoking was a primary cause of lung cancer was published in $1950 .{ }^{21-23}$ Throughout the 1950s, new evidence that smoking caused lung cancer and other health problems continued to accumulate. Studies reported on the induction of cancer by cigarette components in animal models, ${ }^{24}$ the results from large prospective cohort studies, ${ }^{25} 26$ and histopathological findings in humans. ${ }^{27}{ }^{28}$ Also, many researchers replicated the associations suggested in earlier work. $^{29}$

The tobacco industry was quick to respond to this evidence. In January 1954, just before the reports on the cohort studies were to be released, the industry followed the advice of their public relations firm and published a full page advertisement in 448 newspapers across the country announcing the establishment of 
the Tobacco Industry Research Committee (TIRC), with a research budget to "thoroughly investigate the issue of whether smoking caused cancer." ${ }^{\prime 17}$ Key to this damage control strategy was the recruitment of a recognised medical scientist, Clarence "Pete" Little, who had considerable credibility in the cancer field. ${ }^{17}$ Despite the fact that very little TIRC funded research addressed the core smoking and health issues, for many years Little and the TIRC were very effective in obtaining widespread media coverage for a dissenting view of the scientific, peer reviewed evidence that smoking caused cancer and other health problems.

The public health community first presented a consensus statement on the issue of the causal association of smoking to adverse health in 1957, following a thorough review of the evidence by a committee representing the major US public health agencies (the National Cancer Institute, the National Heart Institute, and the American Cancer Society) and led by the US surgeon general. ${ }^{29}$ Similar public health consensus reviews were undertaken at the same time in many western countries over the next few years. ${ }^{30-32}$ However, two leading statisticians of the time, J Berkson and RA Fisher, published papers questioning the causal conclusion, maintaining that alternate interpretations could not be ruled out, given the study designs used. ${ }^{33-35}$ Following another review of the evidence, the surgeon general took the unusual step of publishing a special statement reaffirming causality in the fournal of the American Medical Association. ${ }^{36}$

Meanwhile, the lack of consensus in the US medical community, in contrast to the public health community, was apparent from the action of the New England Fournal of Medicine, which, in 1961, solicited articles from the leading scientific advocate for the public health viewpoint, Ernst Wynder, and from Little of the TIRC. ${ }^{37}$ The accompanying editorial advised the medical audience that they should weigh the evidence for each side and make up their own minds about which to believe. ${ }^{39}$ This equivocation was not evident in the medical community in the UK; the Royal College of Physicians began its own review of the scientific evidence in the late $1950 \mathrm{~s}^{30}$ and presented a very influential report concluding a causal association in $1962 .{ }^{40}$ This evidence of a medical consensus in the UK was sufficient to ensure that a presidential inquiry was initiated in the USA. ${ }^{17}{ }^{21}$ The resulting 1964 surgeon general's report is widely recognised as the definitive review of the data and the beginning of the public health agencies' campaign against smoking in the USA. ${ }^{18}$ The controversy and the events leading up to the 1964 surgeon general's report are documented in a report prepared by the American Cancer Society. ${ }^{41}$

In summary, from 1954 to 1963 , the tobacco industry vigorously countered each new piece of scientific evidence linking smoking to health, and the medical community lagged behind the public health community in its acceptance of the evidence, leading to what could be perceived by the public as a lack of consensus.

\section{Synopsis of important public health policy interventions}

In 1965, after considerable debate, Congress passed the federal Cigarette Labeling and Advertising Act that required a health warning on all cigarette packages. In 1967, innovative legal action by a public health advocate led to a ruling that the "Fairness Doctrine", which allowed free air time to state opposing views on matters of public controversy, was applicable to cigarette advertising. As a result, any television or radio station broadcasting a cigarette commercial was required to donate air time for anti-smoking public service announcements; this resulted in the first public health anti-smoking advertising campaign. This campaign was associated with a downturn in US per capita cigarette consumption. ${ }^{42}$ In 1971, with the acquiescence of the tobacco industry, Congress banned all broadcast media cigarette advertising, and this action also terminated the anti-smoking public service announcements.

In 1965, a special government agency, a national clearing house for smoking and health, was created, and it established a tradition of regular surgeon general's reports for updating the evidence concerning smoking and health. The release of these reports presented a regular newsworthy event for the public health authorities. The 1972 surgeon general's report introduced the concept that cigarette smoke could also harm the health of non-smokers. ${ }^{43}$ Consequently, in 1973, nonsmoking sections were required on all domestic commercial airline flights, and the first state law restricting smoking in public places was enacted. ${ }^{18}$ In the $1980 \mathrm{~s}$, local ordinances restricting smoking in public places became widespread. ${ }^{18} 44$

While the 1964 surgeon general's report brought consensus to the medical and public health communities that smoking was harmful to health, there was not always agreement concerning appropriate approaches to improve public health. In particular, the extreme difficulty many smokers experienced in quitting led to suggestions that cigarettes could be made less harmful. Results from a study published in 1976 suggested that low tar, low nicotine cigarettes (achieved by the tobacco industry at that time by use of a filter) might ameliorate cancer risk, ${ }^{45}$ and another study published in 1979 suggested smokers using filtered cigarettes over many years might have reduced risk. ${ }^{46}$ With strong tobacco industry support, the issue of a "safe" cigarette became a media event in 1978, capturing the front cover of Newsweek. This event followed the publication in major scientific journals by a senior figure at the National Cancer Institute of an assertion that a "safe" cigarette was possible. ${ }^{47}{ }^{48}$ Media coverage of this issue was short lived; the Secretary of Health and Human Services acted swiftly to remove the health official from his leadership position. ${ }^{17}$ However, the power of this message for smokers was evident from the striking increase in sales of 
brands of cigarettes promoted as "low tar". The market share for brands yielding $15 \mathrm{mg}$ or less tar went from $8.9 \%$ in 1974 to $44.8 \%$ in $1980 .^{49}$

In this historical research study, we looked for evidence linking smoking behaviour to levels of news media coverage. We hypothesised that the number of smokers who successfully quit in any given year would be related to the prominence of smoking and health issues in the news media during that year. Further, from communications research, ${ }^{14}$ we expected that the strength of the association would be ameliorated during periods when there was lack of consensus among the important health advocacy groups (for example, between 1954 and 1963, over the causality issue and between 1978 and 1980, surrounding the "safe" cigarette controversy). It would also be expected that smoking behaviour would change as the public increasingly came to accept that smoking harmed the health of smokers and non-smokers. We also anticipated that news media coverage would have less impact on smoking initiation among young people, who generally pay less attention to news media than adults. ${ }^{50}$

\section{Methods}

DATA SOURCE FOR MEDIA COVERAGE OF SMOKING AND HEALTH

Following the approach of Funkhauser, ${ }^{11}{ }^{12}$ we used The Reader's Guide to Periodical Literature to estimate the level of media attention given to issues related to smoking and health. The Reader's Guide catalogues the titles of all magazine articles appearing in the top 125 or so magazines published in the USA each year. ${ }^{51}$ Selection of the magazines indexed is undertaken every few years by voting lists supervised by a committee of the American Library Association. The criteria are that The Reader's Guide "will index periodicals of broad, general and popular character . . to provide a well-balanced selection of US popular non-technical magazines." 52

We counted the number of articles listed under relevant tobacco related headings in The Reader's Guide between 1950 and 1990. Articles were listed under the general topic headings of cigarettes, smoking, and tobacco. In some years there were separate headings for cigarette filters, cigarette holders, cigarette industry, cigarette paper, and cigarette smoke, and when these headings were present, appropriate articles under them were counted as well. Articles dealing with tobacco industry business or marketing practices were excluded unless they mentioned health related issues. The tabulation of the health related articles was completed in 1991 (for the purpose of correlating numbers of articles with important tobacco related events); the development of the incidence measures for cessation and initiation did not begin until several years later. To place the numbers of articles indexed in context, we read all the identified articles from 1950 through 1962, and, thereafter, any articles where the title was unrevealing, and all the articles appearing in Newsweek, The Reader's
Digest, and The Saturday Evening Post. We chose these magazines because they were general interest publications, they had high circulation, and they contained greater coverage of smoking and health issues over the years than other publications.

DATA SOURCE FOR POPULATION BELIEFS REGARDING SMOKING AND HEALTH

We reproduced data presented in the 1989 surgeon general's report $^{18}$ describing survey results on public opinion that "cigarette smoking causes lung cancer" (chapter 4, table 8) and that "smoking is hazardous to nonsmokers health" (chapter 4, table 13). These data were from multiple population surveys conducted by Gallup (1954, 1957, 1958, 1969, 1971, 1977, 1978, 1981, 1987), the National Health Interview Surveys (NHIS) (1985), the Adult Use of Tobacco Surveys (1964, 1966, 1986), and Roper (1974, 1976, 1978). The survey questions and methodology are described in the 1989 surgeon general's report. ${ }^{18}$ Where data were not available for 1983, but were available for a year shortly thereafter, we used linear interpolation to estimate a value for 1983.

DATA SOURCES FOR INCIDENCE OF SMOKING INITIATION AND CESSATION

Incidence of smoking initiation

We have previously reported in detail the methodology we use to assess the annual incidence of initiation in young people. ${ }^{53}{ }^{54}$ Briefly, we use self-reported weighted data from the NHIS (1970, 1978, 1979, 1980, 1987 and 1988) which asked smokers, "How old were you when you started smoking fairly regularly?" In this analysis, we included smokers who were between 20 and 50 years of age when interviewed. Data on individuals younger than 20 years were omitted to avoid interpretive issues related to completion of the smoking uptake process. An upper age limit of 50 years was used to avoid any bias that might be introduced by differential mortality experienced by smokers compared to non-smokers. ${ }^{55}$ Overall, this analysis considered 102626 respondents.

We determined the age of each respondent in two year intervals from 1950-51 through 1982-83. For the computation of the initiation incidence rate, the sum of the weights for all persons eligible to initiate in each interval was the denominator, and the numerator was the sum of the weights for all persons whose reported age of starting fairly regular smoking fell within the interval. Incidence rates were computed for males and females in two age groups (14-17 years and 18-21 years).

\section{Incidence of smoking cessation}

We adapted the above approach to compute the incidence of successful smoking cessation. Smoking supplements to the NHIS in 1965-66, 1970, 1978, 1979, 1980, 1983, 1985, 1987, 1988, 1990, 1991, and 1992 asked all former smokers about how long ago it had been since they last smoked cigarettes fairly regularly. Following previous research, ${ }^{56}$ we 


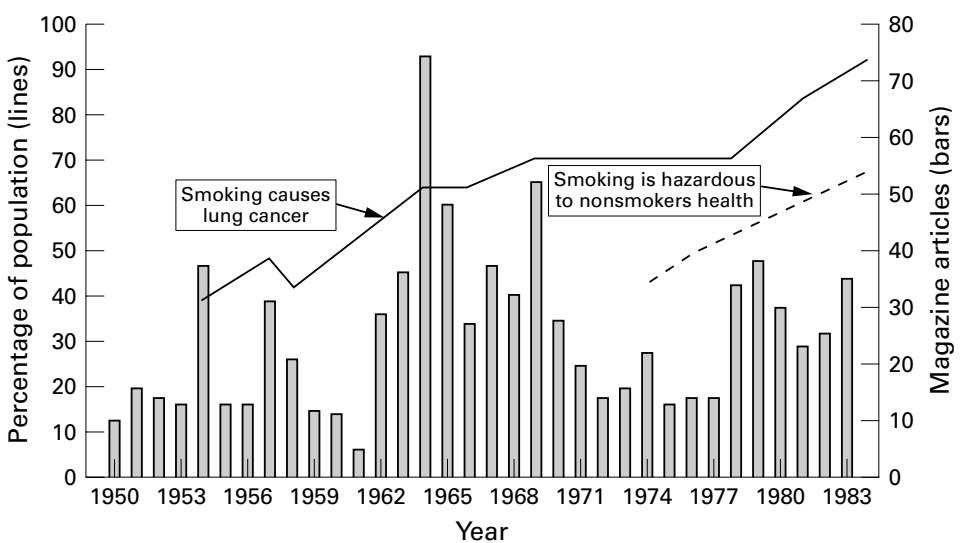

Figure 1 Population beliefs on the harmfulness of smoking (left axis), and annual number of articles on smoking and health indexed in The Reader's Guide to Periodical Literature (right axis).
Guide to Periodical Literature is presented in fig 1. Below we comment on the changes in the numbers of articles in the context of the smoking and health issues receiving media attention. In the first few years of the 1950s, there were less than 20 magazine articles on smoking and health each year, with many addressing the findings of the early case-control studies. The highest coverage in the 1950s occurred in 1954 with 37 articles, many of which focused on the cohort studies $^{25} 26$ and/or the animal study, in which cigarette tar induced cancer. ${ }^{24}$ Starting in 1954, articles were generally accompanied by a highlighted sidebar response from the TIRC, often authored by Little, indicating that more research was required to establish that smoking harmed health.

There was another spike in media coverage in 1957, coincident with the public health consensus publication concluding that smoking caused cancer. ${ }^{29}$ Again, many of the articles included a sidebar for the TIRC response. However, the follow up public health consensus statement of the surgeon general in $1959^{36}$ received little media attention. The next increase in media attention occurred in 1962, when the Royal College of Physician's report ${ }^{40}$ was released. However, the TIRC response, if present at all, was not highlighted in these articles. The highest peak in magazine coverage over the entire period from 1950 to 1983 was 75 articles, which occurred surrounding the release of the 1964 surgeon general's report. ${ }^{21}$ From 1967 to 1970, many of the more than 30 magazine articles each year concerned the impending regulation of the tobacco industry. In 1967 and 1968, articles about the warning labels on packages were common. In 1969, the anti-smoking messages of the "Fairness Doctrine" were highlighted; in 1970, the proposed ban of tobacco advertising in the broadcast media was featured.

The number of articles indexed each year was lower from 1971 to 1977 , with topics typically covering newly discovered health consequences of smoking, including harmful effects to the fetus and to women taking birth control pills, as well as the harm to non-smokers from secondhand smoke. Again, there were 30 or more magazine articles in 1978 to 1980 , many of which covered the potential for development of a "safe" cigarette. There were also a number of articles in 1979 and 1980 that covered the surgeon general's report focusing on the health risks of smoking to women. ${ }^{59}$

Figure 1 also shows the trends for population beliefs about the association between smoking and lung cancer and about the harmfulness of smoking to non-smokers. Less than half of the population believed that smoking caused lung cancer in the 1950s, but this perception increased slowly to just over $60 \%$ when the 1964 surgeon general's report was released. ${ }^{21}$ It rose to approximately $70 \%$ during the "Fairness Doctrine" anti-smoking advertising campaign, and it remained fairly stable until the late 1970s, when it again increased greatly to over $90 \%$ by the early 1980s. The percentage of the population believing that smoking is hazardous to BELIEFS

The number of articles on smoking and health each year in magazines indexed by The Reader's 


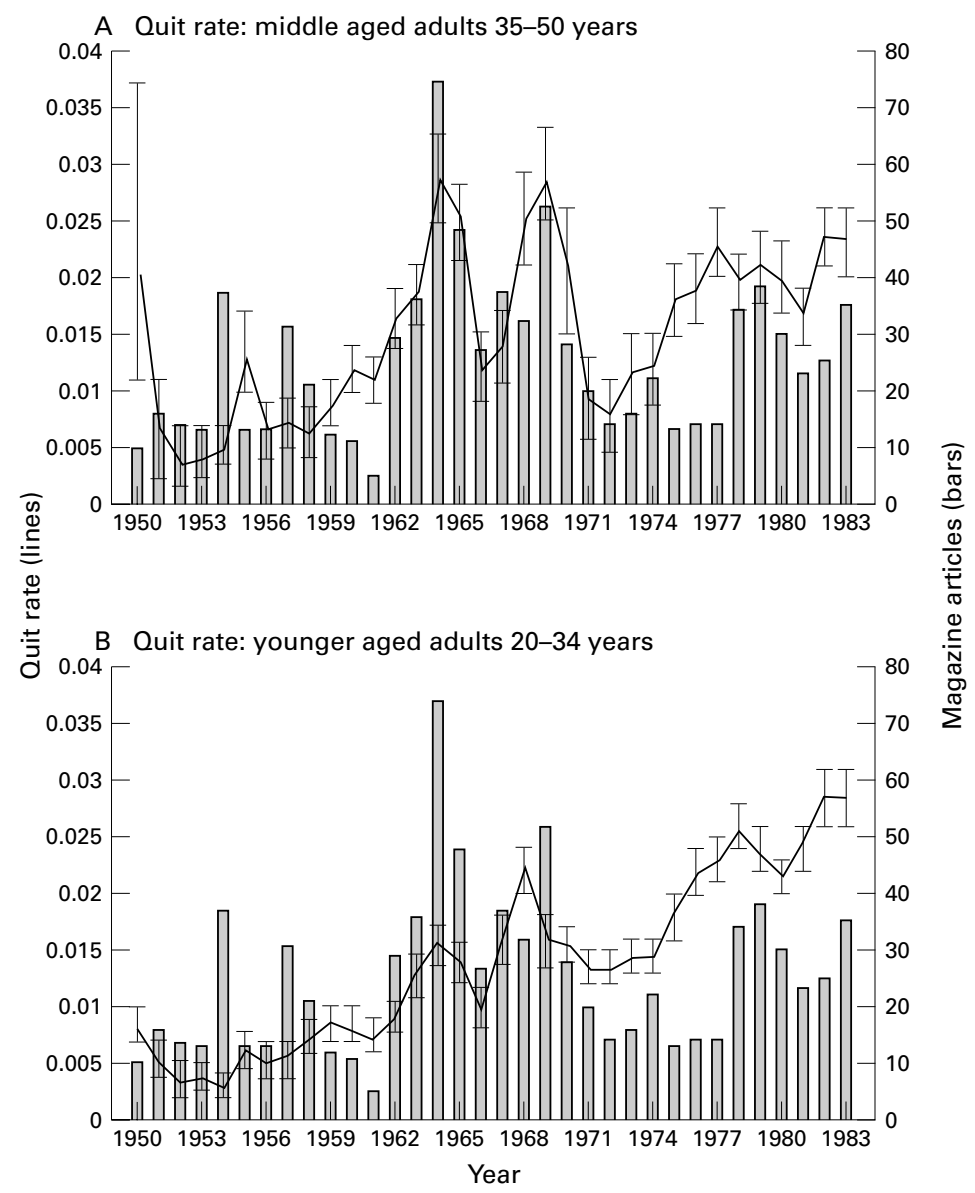

Figure 2 Annual incidence of successful smoking cessation (left axis) for middle aged smokers (A) and for younger smokers (B), and annual number of articles on smoking and health indexed in The Reader's Guide to Periodical Literature (right axis).

non-smokers' health was below $50 \%$ in 1974 , when this belief was first monitored, but it approached $70 \%$ by the early 1980 s.

INCIDENCE OF SUCCESSFUL SMOKING CESSATION In previous analyses, we noted that the pattern of incidence of successful smoking cessation differed notably by age but not much by sex. ${ }^{60}$ Accordingly, we present the incidence data separately for middle aged adults (35-50 years) and young adults (20-34 years) in fig 2.

Among the middle aged, the incidence of successful cessation was less than $0.5 \%$ per year before 1955 (except for 1950), but it increased approximately fivefold to $2.5 \%$ by 1983 . The annual incidence rate appears to track closely the trend in the annual number of news media articles. We computed the successful cessation rates before 1950, and these were near zero (not shown). There was a spike in successful quitting in 1950, the year the first evidence on smoking and lung cancer was made public, ${ }^{22} 23$ and another spike in 1955, the year after over 37 articles on smoking appeared in 1954.

While the 1957 public health consensus review $^{29}$ was well covered in the media, it was not associated with an increase in successful cessation. Rather, cessation in the middle aged increased gradually to a peak of over $2.5 \%$ per year in 1964, when the surgeon general's report $^{21}$ was released. Cessation declined rapidly with declining media coverage in 1965 and 1966, but it increased quickly again between 1967 and 1969, coincident with the increased media coverage, as well as the first anti-smoking television commercials. The removal of all radio and television tobacco advertising and counter advertising as of January 1971 was associated with a rapid decrease in the incidence of cessation to less than $1 \%$ per year in 1971 and 1972 . Cessation rates in 1975 through 1977 were higher than would be expected from the way they had tracked previous media coverage, which may reflect the salience of the message that smoking harms the health of non-smokers. A decline in cessation was noted in the years from 1978 to 1981, the years of the "safe" cigarette controversy.

Successful cessation in young adults also had an underlying upward trend across the study period, and by 1983, the incidence of cessation (nearly 3\% per year) was slightly higher than for middle aged adults. As with middle aged adults, the incidence of successful cessation generally followed the level of media attention, although the effect was more muted, especially from 1950 though 1967. Indeed, the cessation rate in 1964 was only half that observed for middle aged adults. However, coincident with the first anti-smoking television advertising campaign, cessation rates in younger smokers increased more notably. The decline in successful cessation following the termination of this programme was less pronounced than the decline observed in middle aged smokers. As with the middle aged, successful cessation increased rapidly as the population adopted the belief in the harm of smoking to non-smokers. Younger adults also showed a decline in cessation in 1979 and 1980.

INCIDENCE OF SMOKING INITIATION

Our earlier analyses of these data ${ }^{53}$ showed that persons aged 14-21 years had the highest incidence of initiation over the study period; within this age range, the pattern differed greatly by sex and age. Thus, incidence of initiation is presented for two age groups (14-17 years and 18-21 years) for each sex in fig 3.

Throughout the 1950s, the incidence of smoking initiation in 18-21 year old young men was very high (12-14\% per year), and there were no abrupt changes to indicate that the rate was affected by media coverage of issues related to smoking and health. However, initiation started to decline in 1968-69, coincident with the first anti-smoking television commercials, and it declined fairly consistently thereafter. By 1982-83, initiation was about $5 \%$ per year.

Throughout the 1950s, incidence of initiation in 14-17 year old boys was approximately one third lower (around 9\% per year) than for 18-21 year old young men. Incidence of initiation in the younger age group appeared to be largely unaffected by any event from 1950 through the early 1970s, after which it began to decline. By 1982-83, incidence of initiation appeared slightly higher than that for young men at just over $6 \%$ per year.

The incidence of smoking initiation in 18-21 year old young women was approximately $8 \%$ 


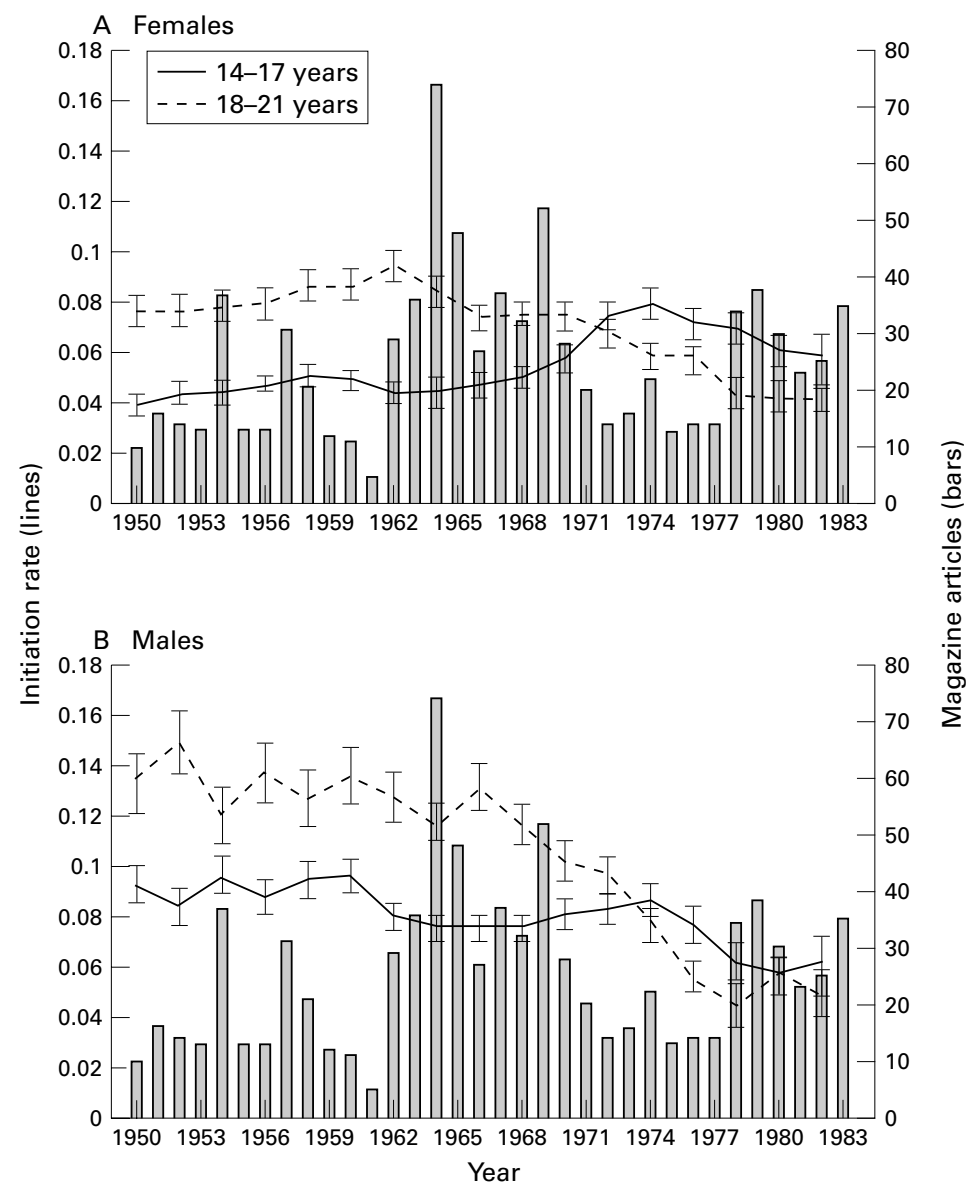

Figure 3 Biannual incidence of initiation of regular smoking (left axis) for female young adults and adolescents (A) and for male young adults and adolescents (B), and annual number of articles on smoking and health indexed in The Reader's Guide to Periodical Literature (right axis). and low rates of coverage in intervening years. The incidence of successful smoking cessation followed a pattern remarkably similar to the level of media coverage, particularly among middle aged smokers. This relation was absent during periods of controversy among the various advocacy groups. Cessation increased as the population adopted the belief that smoking harms the health of non-smokers. Finally, the incidence of smoking initiation in young people did not appear to change in response to media coverage.

The pattern of successful quitting among young adult smokers also followed the oscillating trend of the news media coverage; however, these fluctuations were considerably dampened compared to those in the middle aged smokers. Further, for the years from 1950 to 1967, quit rates were approximately half those of the middle aged smokers. This situation changed in the period from 1967 to 1983 , so that the cessation rate was higher in younger smokers than in the middle aged by 1983 . The beginning of the reversal in cessation level was coincident with the first anti-smoking campaign using the broadcast media. Perhaps younger smokers were greater consumers of these media than of the print media, so the lower rates during the period before 1967 could be explained by less exposure to the message that smoking harms health. However, the earlier period was mostly before there was a clear consensus that smoking harmed health. It is possible that middle-aged smokers were more responsive to the scientific data, since they were closer in age to when the health consequences of smoking were likely to occur. During the 1970s, the average state and federal excise tax on cigarettes ranged from $\$ 0.19$ to $\$ 0.20$ per pack, ${ }^{61}$ and the average real price of cigarettes did not increase between 1972 and $1981 .{ }^{18}$ Thus, it was unlikely that higher cigarette price induced increased quitting during this period. Perhaps the rise in the belief in the population that secondhand smoke was harmful encouraged quitting. The message that "your smoking harms others" has since been shown to be a strong motivator for smokers to quit. ${ }^{62}{ }^{63}$ Also, during this period, restrictions on smoking in public places, including the workplace, began to be adopted, and such restrictions have since been shown to reduce smoking. ${ }^{64}$

The decreased media attention to a smoking related issue after it was no longer newsworthy may itself account for the abrupt declines in cessation incidence following pronounced peaks that tracked the media coverage. However, smokers ready to quit may have accelerated their quit, possibly in response to intense news media attention to a health issue, leaving behind a less motivated group. A few years may then have had to pass before this group of less motivated smokers became receptive to quitting, resulting in lower quit rates immediately after the peak levels.

As we previously described, there were two periods during which there was not consensus in the public health and medical communities. The first period was about the scientific 
evidence linking smoking to harmful health effects, and the later period concerned the public policy directions about the development of less harmful cigarettes. During the earlier period, the news media gave TIRC the right of refutation (with highlighted sidebars) of every new piece of scientific evidence. However, when the medical community finally closed ranks with the public health community, the media no longer highlighted the issue as controversial. The later period of apparent lack of consensus occurred in 1978, when a senior official in the National Cancer Institute Cancer prevention programme suggested that a "safe" cigarette could be produced. During the first period of controversy, the incidence of successful cessation failed to track the level of media coverage. This also occurred during the "safe" cigarette controversy; in fact, while media coverage increased, cessation rates actually declined. Sales of cigarette brands labelled as lower in tar and nicotine increased greatly, ${ }^{49}$ suggesting that a number of smokers switched to these "safe" brands instead of quitting.

Dissemination of the scientific evidence linking smoking to adverse health had no discernable effect on the incidence of initiation of smoking during the 1950s. With the beginning of the public health campaign in the 1960 s, young adults began to show declines in smoking initiation. Adolescents did not show declines in initiation until the 1970s. There are two reasonable explanations for the lack of effect on adolescents: (1) adolescents were not exposed to the message that smoking effects health, or (2) if exposed, they were not as receptive to the message. Most of the magazine articles we reviewed appeared in magazines with primarily adult audiences; nonetheless, it is possible that adolescents might have been exposed to messages in media not covered by The Reader's Guide, and simply paid little attention. Messages about the health consequences of smoking have not been shown to be salient to adolescents. ${ }^{6566}$

The incidence of smoking initiation in adolescents only started to decline a few years after the broadcast ban on cigarette advertising. Previous research has shown that adolescents are receptive to tobacco industry advertising and promotions, and that such receptivity is associated with adolescents beginning the process of becoming a smoker. ${ }^{3}$ However, the uptake process continues over several years, ${ }^{67} 68$ so a lag before a reduction in initiation of regular smoking is seen as still consistent with the decline in initiation being related to the advertising ban. Yet, we cannot rule out other explanations. The year 1974 marked the beginning of a period of increased smoking cessation in both younger and middle aged adult smokers, and it was also the start of the long and consistent decline in US per capita sales of cigarettes. $^{18}$ These trends suggest that there was an important change in the social milieu relating to smoking in the USA, and this development could also have led to reduced adolescent smoking initiation.

There are a number of limitations to these data. We reconstructed the incidence of
What is already known on this subject

Very little is known about the role that the news media play in influencing health related behaviour. However, universities, journals and a number of investigators go to considerable length to ensure that their research publications are covered in the news media.

\section{What this paper adds}

This study is the first to look systematically at the coverage of smoking in the print media and correlate it with the incidence of population smoking behaviour. Coverage in the print media was correlated with adult quitting behaviour but not adolescent initiation behaviour reflecting the age of consumers of print media. This study suggests that a high emphasis should be given to the role of news media in encouraging adults to change their behaviour for health reasons.

successful cessation using former smokers' recall of when they quit, possibly years earlier for many. There is considerable evidence that recall of events for surveys can be erroneous. ${ }^{69}$ Given this, it is surprising that the fluctuations in the estimated quit rates matched the oscillations in news media coverage so closely. Quitting may be a momentous enough event that smokers have easily accessible memories of when they succeeded. Indeed, the only time early on when there was a lack of correspondence between the two measures was in 1954 and 1955, when quitting spiked one year later than the considerable media coverage of the first reports of the cohort studies. However, the media coverage did not commence until mid 1954. While the use of The Reader's Guide to Periodical Literature is an accepted method for establishing the media attention to an issue, ${ }^{11} 12$ it may not correspond exactly to the level of coverage of smoking and health issues in other news media, such as radio, television, and newspapers. In fact, the level of coverage in some magazines may be considerably less than in other media; previous research indicates that magazines that accept cigarette advertising have lower coverage of smoking and health issues than other magazines and other news media. ${ }^{70-72}$

IMPLICATIONS

Our results indicate that news media coverage can be an important factor in changing population smoking behaviour and have broad implications for tobacco control programmes in the USA and abroad. Tobacco control advocates should give high priority to promoting newsworthy tobacco related events to journalists. In countries with high smoking rates, such as those in southern and eastern Europe, the scientific evidence concerning the health consequences of smoking may not have received wide coverage or have been well presented in the local media. International tobacco control and health advocates or such 
advocates within countries with high smoking prevalence should work diligently to increase the level of media attention devoted to issues related to smoking and health.

Preparation of this article was supported by the Cancer Prevention Research Unit, Grant CA 72092, funded by the National Institutes of Health, Bethesda, Maryland.

1 Pierce JP, Gilpin EA. A historical analysis of tobacco marketing and the uptake of smoking by youth in the
United States: 1890-1977. Health Psychology 1995; 14:500-8.

2 Pollay RW, Siddarth S, Siegel M, et al. The last straw? Cigarette advertising and realized market shares among youths rette advertising and realized market shares among

3 Pierce JP, Choi WS, Gilpin EA, et al. Tobacco industry promotion of cigarettes and adolescent smoking. FAMA. 1998;279:511-15.

4 Biener L, Siegel M. Tobacco marketing and adolescent smoking: more support for a causal inference. Am f Pub Health 2000;90:407-11

5 Warner KE. Effects of antismoking campaign: an update. Am F Pub Health 1989;79:144-51.

6 Pierce JP, Macaskill P, Hill D. Long term effectiveness of mass media led anti-smoking campaigns in Australia. Am Pub Health 1990;80:565-9.

7 Macaskill P, Pierce JP, Simpson JM, et al. Mass media let antismoking campaign can reduce the education gap in quitting behavior. Am f Pub Health 1990;82:96-8.

8 Pierce JP, Anderson DM, Romano RM, et al. Promoting smoking cessation in the United States: effects of public service announcements on the Cancer Information
Service Telephone Line. 7 Natl Can Inst 1992;84:677-83.

9 Siegel M, Biener L. The impact of an antismoking media campaign of progression to established smoking: results of a longitudinal youth study. Am F Pub Health 2000;90:380-6.

$10 \mathrm{McCombs}$ ME, Shaw DL. The agenda-setting function of the mass media. Public Opinion Quarterly 1972;36:176-87.

11 Funkhauser GR. The issues of the sixties: an exploratory study in the dynamics of public opinion. Public Opin Quarterly 1973;37:62-5.

12 Funkhauser GR. Trends in media coverage of the issues of the sixties. Fournalism Quarterly 1973;50:533-8.

13 Dearing JW, Rogers EM. Communications Concepts 6, Agenda-setting. Thousand Oaks, California: Sage Publications, 1996.

14 Baumgartner FR, Jones BD. Agendas and instability in American politics. Chicago, Illinois: The University of ChiAmerican politics.

15 Meyer P. News media responsiveness to public health. In: C Atkin and L Wallach, eds. Mass communications and public health. Complexities and conflicts. Newbury Park, California: Sage Publications; 1990:52-9.

16 Glantz SA, Balbach ED. Tobacco war. Inside the California battles. Berkeley, California: University of California Press, 2000.

17 Kluger R. Ashes to ashes. America's hundred-year cigarette war, the public health, and the unabashed triumph of Philip Morris. New York: Alfred A Knopf, 1996.

18 US Department of Health and Human Services. Reducing the health consequences of smoking: 25 years of progress. A report of the Surgeon General, 1989 . Rockville, Maryland: on Smoking and Health, 1989. (DHHS Publication No (CDC) 89-8411.)

19 Wynder EL. The past, present, and future of the prevention of lung cancer. Cancer Epidemiol Biomarkers Pre 1998;

20 Doll R. Tobacco: a medical history. Fournal of Urban Health: Bulletin of the New York Academy of Medicine 1999;76:289313.

21 US Department of Health and Human Services. Smoking and health. Report of the Advisory Committee to the Surgeon General of the Public Health Service. US Department of Health, Education, and Welfare, Public Health Service, Center for Disease Control, 1964. (PHS Pub. No. 1103.)

22 Doll R, Hill AB. Smoking and carcinoma of the lung. Preliminary report. BM7 1950;2:739-48.

23 Wynder EL, Graham EA. Tobacco smoking as a possible etiologic factor in bronchiogenic carcinoma. A study of etiologic factor in bronchiogenic carcinom

24 Wynder EL, Graham EA, Croninger AB. Experimental production of carcinoma with cigarette tar. Cancer Res duction of carcino

25 Doll R, Hill AB The mortality of doctors in relation to their smoking habits: a preliminary report. BMF 1954;1:1451-5.

26 Hammond EC, Horn D. The relationship between human smoking habits and death rates: a follow-up study of 187,766 men. FAMA 1954;154:1316-28.

27 Auerbach O, Petrick TG, Stout AP, et al. The anatomical approach to the study of smoking and bronchogenic carcinoma : a preliminary report of 41 cases. Cancer 1956;9:76-83.

28 Auerbach O, Gere JB, Forman JB, et al. Changes in the bronchial epithelium in relation to smoking and cancer of the lung. N Engl f Med 1957;256:97-104.

29 Study Group on Smoking and Health. Joint report of study group on smoking and health. Science 1957;125:1129-33.

30 Medical Research Council. Tobacco smoking and cancer of the lung. BMF 1957;1:1523-4.
31 Swedish Medical Research Council. Statement to the King. May $12,1958$.

32 World Health Organization. Epidemiology of cancer of the lung. Report of a study group. Geneva, Switzerland: World Health Organiaztion; 1960. World Health Organization Technical Report Series 192

33 Berkson J. The statistical study of association between smoking and cancer. Proc Mayo Clin 1955;30:319-48.

34 Berkson J. Smoking and lung cancer: some observations on two recent reports. F Am Stat Assoc 1958;53:28-38.

35 Fisher RA. Cancer and smoking. Nature 1958;182:596-7.

36 Burney LE. Smoking and lung cancer: a statement of the public health service. $\mathcal{F A M A} 1959 ; \mathbf{1 7 1} ; 1829-37$.

37 Wynder EL. An appraisal of the smoking-lung cancer issue. N Engl F Med 1961;264:1235-40.

38 Little CC. Some phases of the problem of smoking and lung cancer. $N$ Engl $\mathscr{f}$ Med 1961;264:1241-5.

39 Anon. The great debate [editorial]. $N$ Engl $f$ Med 1961;264:1266.

40 Royal College of Physicians. Smoking and health. Summary and report of the Royal College of Physicians of London on Smoking in relation to cancer of the lung and other diseases. New York: Pitman Publishing, 1962.

41 American Cancer Society. The position of the American Cancer Society regarding tobacco and lung cancer. New York: American Cancer Society News Service, 1964

42 Warner KE. Cigarette smoking in the 1970's: the impact of the antismoking campaign on consumption. Science 1981; 211(4483):729-31.

43 US Department of Health, Education and Welfare. The health consequences of smoking. A report of the Surgeon General, 1972. Washington, DC: National Clearinghouse for Smoking and Health, 1972. (DHEW Publication No (HSM) 72-7516.

44 US Department of Health and Human Services. Major local tobacco control ordinances in the United States. Smoking and Tobacco Control Monograph No 3. Bethesda, Maryland: Public Health Service, National Institutes of Health, 1993. Public Health Service, National Inst

45 Hammond EC, Garfinkel L, Seidman H, et al. "Tar" and nicotine content of cigarette smoke in relation to death rates. Environ Res 1976;12:263-74.

46 Wynder EL, Stellman SD. Impact of long-term filter cigarette usage on lung and larynx cancer risk: a case-control study. F Natl Can Inst 1979;62:471-77.

47 Gori GB. Low-risk cigarettes: a prescription. Science 1976;194:1243-6.

48 Gori GB, Lynch CJ. Toward less hazardous cigarettes. Current advances. $\mathcal{F} A M A$ 1978;240:1255-9.

49 Federal Trade Commission. Report to Congress for 1994 Pursuant to the Federal Cigarette Labeling and Advertisement Act. Washington DC: Federal Trade Commission, 1994.

50 Slater MD. Integrating application of media effects, persuasion, and behavior change theories to communications campaigns: a stages-of-changes framework. Health Communications 1999;11:335-54.

51 The Reader's Guide to Periodical Literature. An Author and Subject Index. Vol 17-Vol 42. New York: The HW Wilson Company, 1951-1983.

52 The Reader's Guide to Periodical Literature. An Author and Subject Index. Vol 28. New York: The HW Wilson Company, 1969.

53 Gilpin EA, Lee L, Evans N, et al. Smoking initiation rates in adults and minors: United States, 1944-1988. Am f Epidemiol 1994;140:535-43.

54 Pierce JP, Lee L, Gilpin EA. Smoking initiation by adolescent girls 1944-1988: an association with targeted advertising. FAMA 1994;271:608-11.

55 Doll R, Peto R, Wheatley K, et al. Mortality in relation to smoking: 40 years observation on male British doctors. BMF 1994;309:901-11.

56 Gilpin EA, Pierce JP, Farkas AF. Duration of smoking abstinence and success in quitting. I Natl Can Inst 1997; 89:572-6.

57 Doll R, Grey R, Hatner B, et al. Mortality in relation to smoking. 22 years observations on British doctors. BMf 1980;280:967-71.

58 Shah BV, Barnwell BG, Bieler GS, et al. SUDAAN software for the statistical analysis of correlated data. Technical manual. Statistical methods and algorithms used in SUDAAN. Release 7.0. Research Triangle Park, North Carolina: Research Triangle Institute, 1996.

59 US Department of Health, Education and Welfare. The health consequences of smoking 1977-1978. Rockville, Maryland: US Department of Health, Education, and Welfare, Public Health Service, Office of the Assistant Secretary for Health, Office on Smoking and Health, 1979. (DHEW Publication No (PHS) 79-50065.)

60 Gilpin EA, Pierce JP. Demographic differences in the patterns in the incidence of smoking cessation: United States 1950-1990. Submitted 1999.

61 Tobacco Institute. The tax burden on tobacco. Historical compilation, 1995. Washington DC: The Tobacco Institute, 1996

62 Pierce JP, Dwyer T, Chamberlain A, et al. Targeting the smoker in an anti-smoking campaign. Prev Med 1987:16:816-24

63 Gilpin EA, Pierce JP, Goodman J, et al. Reasons smokers give for stopping smoking: do they relate to success in stopping? Tobacco Control 1992:1:256-63.

64 Chapman S, Borland R, Scollo M, et al. The impact of smoke-free workplaces on declining cigarette consumption
in Australia and the United States. Am f Public Health 1999:89:1018-23. 
65 US Department of Health and Human Services. Preventing tobacco use among young people. A report of the Surgeon General. Atlanta, Georgia US Department of Health and Human Services, Public Health Service, Centers for Disease Control and Prevention, National Center for Chronic Disease Prevention and Health Promotion, Office on Smoking and Health, 1994. (US Government Printing Office Publication No S/N 017-001-00491-0.

66 Glynn TJ. Essential elements of school-based smokingprevention programs. $\mathcal{F}$ Sch Health 1989;59:181-8.

67 Baugh JG, Hunter SM, Webber LS, et al. Developmental trends of first cigarette smoking experience of children: the Bogalusa heart study. Am 7 Public Health 1982;72:1161-4.

68 Choi WC, Gilpin EA, Farkas AJ, et al. Determining the probability of future smoking among adolescents. Addiction 2001;96:313-23.
69 National Center for Health Statistics. Health interview responses compared with medical records. Vital and Health Statistics. Washington DC: Public Health Service, US Government printing office, 1965. ( PHS Publication No 1000-Series 2-No. 7.)

70 Whalen EM, Sheridan MJ, Meister KA, et al. Analysis of coverage of tobacco hazards in women's magazines. F Public Health Policy 1981;2:28-35.

71 Albright CL, Altman DF, Slater MD, et al. Cigarette advertisements in magazines: evidence for a differential focus on women's and youth magazines. Health Educ Quarterly 1988;15:225-33.

72 Warner KE. Cigarette advertising and magazine coverage of the hazards of smoking. A statistical analysis. N Engl F Med 1992;326:305-9.

\section{The lighter side}

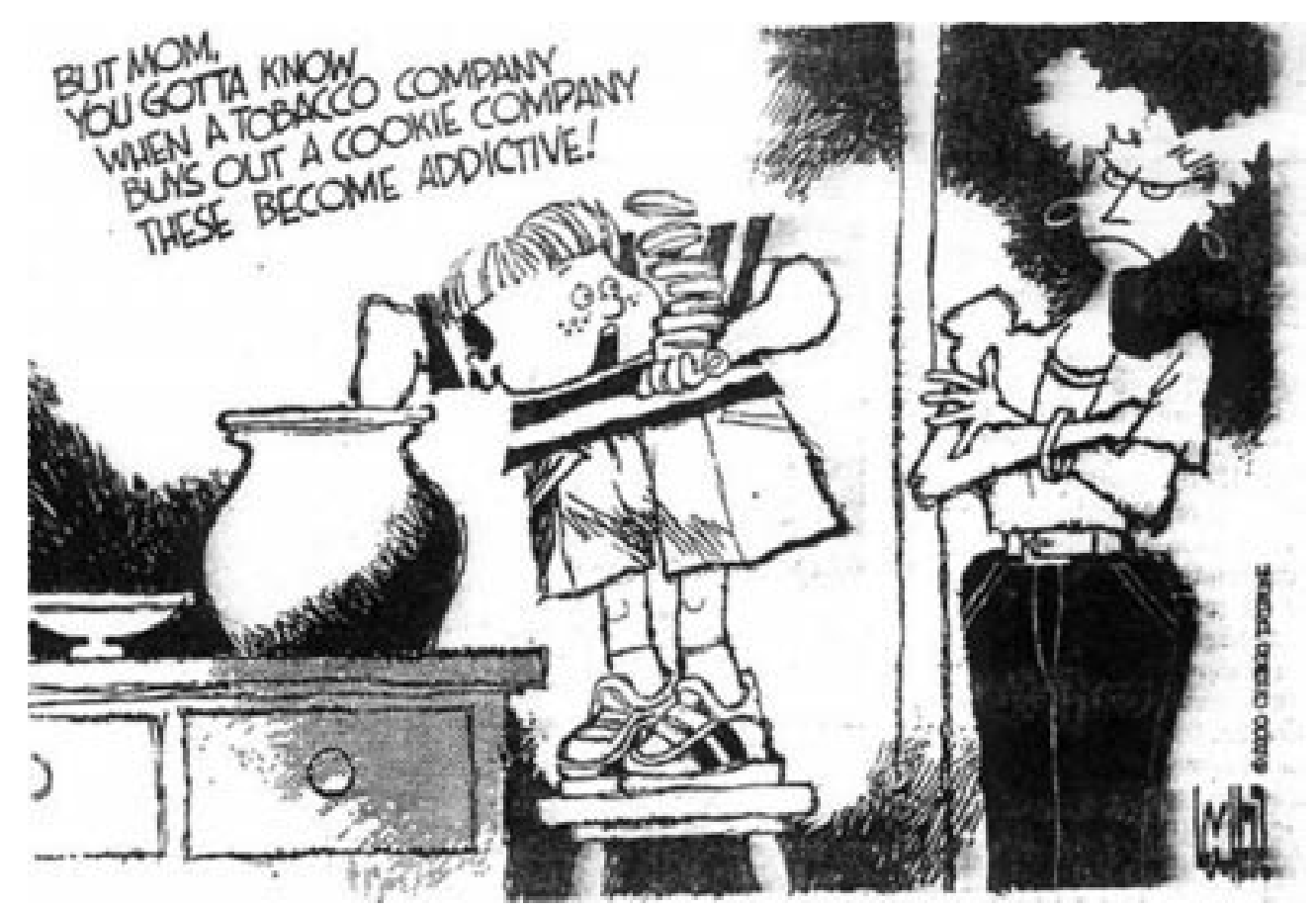

Cookie addict. By Walt Handelsman, reprinted with kind permission of the artist. 